\title{
Clinical efficacy of repeated intra-articular pulsed radiofrequency for the treatment of knee joint pain and its effects on inflammatory cytokines in synovial fluid of patients
}

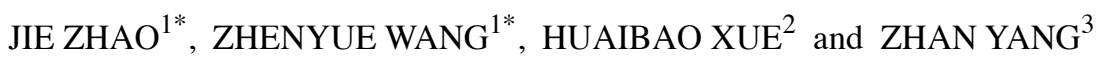 \\ ${ }^{1}$ Department of Orthopaedic Surgery (Osteoarthritis), Caoxian People's Hospital, Caoxian, Shandong 274400; \\ ${ }^{2}$ Department of Orthopedics, Yutai County People's Hospital, Yutai, Shandong 272300; ${ }^{3}$ Department of Bone Surgery \\ (Traumatized Joint Department), Caoxian People's Hospital, Caoxian, Shandong 274400, P.R. China
}

Received October 12, 2019; Accepted June 18, 2021

DOI: $10.3892 /$ etm.2021.10507

\begin{abstract}
The application value of repeated intra-articular pulsed radiofrequency for the treatment of knee joint pain has remained to be determined. To investigate this, a total of 64 patients with chronic knee joint pain admitted to Caoxian People's Hospital (Caoxian, Chine) between October 2016 and May 2018 were enrolled in the present study and analyzed prospectively. The patients were randomly divided into a control group, receiving treatment with a single intra-articular pulsed radiofrequency through the knee joint $(n=32)$, and an experimental group, receiving multiple intra-articular pulsed radiofrequency treatments through the knee joint $(n=32)$. The visual analog scale score (VAS), clinical efficacy and adverse reactions prior to and after treatment were compared between the two treatments. Synovial fluid cytokines were measured using ELISA prior to and after treatment. After the treatment, the control group and the experimental group both had a lower VAS $(\mathrm{P}<0.001)$ and the control group had a higher VAS and lower pain relief than the experimental group $(\mathrm{P}<0.001)$. The control group had a total effectiveness rate of $78.13 \%$, with 13 patients experiencing complete relief (40.63\%), 12 patients exhibiting a marked improvement $(37.5 \%)$ and 7 patients reporting no effects $(21.87 \%)$. The experimental group had a total effectiveness rate of $90.63 \%$, with 18 patients $(56.25 \%)$ being cured, 11 patients having a marked effect (34.37\%) and 3 patients reporting no effects $(9.38 \%)$. The experimental group had a higher incidence of adverse reactions than the control
\end{abstract}

Correspondence to: Dr Zhan Yang, Department of Bone Surgery (Traumatized Joint Department), Caoxian People's Hospital, Fumin Avenue, Cao County Development Zone, Caoxian, Shandong 274400, P.R. China

E-mail: 1pn6cwi@163.com

*Contributed equally

Key words: pulsed radiofrequency, knee joint pain, inflammatory cytokine, synovial fluid group $(\mathrm{P}<0.05)$. After treatment, the two groups had decreased IL-6, IL-10 and TNF- $\alpha$ levels in the knee joint synovial fluid $(\mathrm{P}<0.05)$, with the experimental group having lower cytokine levels than the control group $(\mathrm{P}<0.05)$. These results indicated that repeated intra-articular pulsed radiofrequency is an effective method for the treatment of knee joint pain and may be used in clinical practice.

\section{Introduction}

Knee joint pain, a common morbidity in clinical orthopedics, has various causes. Chronic knee pain is frequently caused by osteoarthritis (OA) (1); in elderly patients, it may be caused by rheumatoid arthritis (2). The knee joint is a complex and important joint (3) and knee joint pain severely reduces the quality of life of patients. In the clinic, treatments to alleviate pain and maintain joint mobility are selected based on the situations of individual patients. Treatment generally includes pain management, physical therapy and replacement therapy, which are usually adopted in combination. In the treatment of knee joint OA, glucosamine combined with chondroitin sulfate have relevant roles in clinical analgesia (4) and non-steroidal anti-inflammatory drugs (NSAIDs) may alleviate pain, though they are not suitable for certain patients due to their side effects, such as injury to the intestinal mucous membrane following their long-term oral use (5-7). Proximal fibula osteotomy, a novel type of surgery, may be adopted to relieve pain and improve joint function in patients, whereas partial or total knee arthroplasty should only be considered when all conservative treatment measures have been attempted (8).

Pulsed radiofrequency is widely adopted to relieve pain in clinical practice (9-11). In this process, a pulsed current emitted by a radiofrequency generator applies a high voltage to the area near the nerve tissue. Such energy transmission will neither destroy the anatomic basis of pain impulse transmission, nor destroy motor nerve function; thus, pulsed radiofrequency is a safe treatment with little risk. Erdem and Sir (12) investigated the effects of ultrasound-guided knee radiofrequency treatment on knee joint pain in patients with severe knee OA or patients who underwent knee arthroplasty and indicated that perceived pain and disability in the knee 
medial nerves were relieved after the treatment. Relevant studies have confirmed that pulsed radiofrequency treatment for the knee joint, a novel technique for relieving pain in $\mathrm{OA}$, is able to reduce pain, relax the muscles and improve knee function (13). Such injuries stimulate large increases in the levels of catabolic species, which contribute to progressive cartilage destruction in the synovial fluid (14). Single pulsed radiofrequency may alleviate pain, but its regulation does not last for a long period of time. To date, only a small number of clinical studies $(15,16)$ have reported the use of repeated intra-articular pulsed radiofrequency for the treatment of knee joint pain.

Studies have indicated that knee OA is associated with inflammatory mediators $(17,18)$. For instance, IL-6- and TNF- $\alpha$-mediated diet and exercise affect the pain associated with knee OA (19). In addition, a recent study suggested that cytokine and neuropeptide levels are associated with pain and pain relief in patients with joint disease (20). Several groups have focused their attention on the potential of IL-10 as a therapeutic tool for OA therapy and prevention $(21,22)$. IL-10 may be a useful marker for systemic inflammatory diseases (23). However, these studies may underestimate the variety of biochemical mediators implicated in long-term outcomes of OA (24). The level of inflammatory mediators may be adopted for a comprehensive diagnosis of patients with knee joint pain and provide an effective reference for successful treatment strategies, such as the main index for the degree and assessment of clinical efficacy.

The present study utilized repeated intra-articular pulsed radiofrequency to treat patients with knee joint pain and observed its clinical efficacy and safety in patients as well as its effects on IL-6, IL-10 and TNF- $\alpha$ levels in the synovial fluid.

\section{Patients and methods}

Subjects. A total of 64 patients with chronic knee joint pain admitted to Caoxian People's Hospital (Caoxian, China) between October 2016 and May 2018 were enrolled in our study and analyzed prospectively. The 64 patients included 31 males and 33 females between the ages of 50 and 60 years with a mean age of $52.23 \pm 11.57$ years. This study was approved by the Ethics Committee of the Caoxian People's Hospital (Caoxian, China) and all subjects signed an informed consent form. Kellgren and Lawrence's radiological diagnostic criteria (25) were used, in which OA is classified into five levels: Grade 0, normal; Grade I, suspected narrowing of the joint space and possible osteophytes; Grade II, obvious osteophytes and the joint space is suspiciously narrowed; Grade III, moderate number of osteophytes, the joint space is narrowed and there are sclerosing changes; Grade IV, a large number of osteophytes, the joint space is notably narrowed and there are severe sclerosing lesions and obvious deformities.

Inclusion and exclusion criteria. The inclusion criteria were as follows: Patients between 50 and 60 years of age for whom complete clinical data were available; diagnosed with knee pain lasting for 0.5-1 years with limited joint activity; presence of a large amount of effusion confirmed by physical examination and MRI; willingness to cooperate with the medical staff at the hospital. The exclusion criteria were as follows: Patients with a history of long-term analgesic drug usage; cardio-cerebrovascular disease; severe organ failure; combined injuryperipheral neuropathy; mental disease or communication obstacles; and those transferred to another hospital half-way through the study period. Patients from whom synovial fluid collection was not successful were also excluded.

Methods. The study only included patients whose knee effusion was confirmed by physical examination and MRI. Synovial fluid was collected either directly or by small volume saline lavage when direct aspiration failed. The patients were randomly divided into a control group, who received treatment with a single intra-articular pulsed radiofrequency through the knee joint $(n=32)$, and the experimental group, who received multiple intra-articular pulsed radiofrequency treatments through the knee joint $(n=32)$. The subjects in the control group were treated once and those in the experimental group were treated once every two weeks (for a total of four times). The treatment period was two months.

Treatment methods. The patients were placed in a supine position on an operating table with a thin pillow under the knee. The patients were locally anesthetized by subcutaneous injection on both sides of the knee joint. Two radiofrequency trocars $(10 \mathrm{~cm}$ long and $10 \mathrm{~mm}$ wide at the working end) were inserted into the knee articular cavity from the knee eyes to the center of the knee joint with assisted positioning using ultrasound-guided radiofrequency (STARmed) manipulation of the sensory nerve around the knee. A radiofrequency therapy device was connected and regulated to have a voltage of $<45 \mathrm{~V}$ and a temperature of $<45^{\circ} \mathrm{C}$, for $15 \mathrm{~min}$. The puncture points were covered with sterile drug film (Kanglidi aseptic dressing; China Yangzhou Guo Tai Co., Ltd.) after treatment. All operations were performed by the same group of physicians and the patients' adverse reactions were closely monitored during the treatment. If infection occurred after the operation, adequate drainage was required, bacterial culture and drug sensitivity tests were carried out on the pus and relevant antibiotics were then used for anti-infection treatment according to the drug sensitivity test.

Evaluation standards of clinical efficacy. The degree of pain in the patients was assessed by determining the visual analog scale score (VAS) prior to treatment and at a minimum of 2 years following surgery (26). The pain was scored as follows: No pain, 0 ; tolerable mild pain, $0-4$; pain that affects sleep, 4-7; and intolerable, severe pain, 7-10.

Treatment efficacy was evaluated as follows: 'Cure' was defined as complete disappearance of knee joint disease and the patient's activity returning to normal; a 'marked effect' was defined as relieved knee joint pain and flexion and improved motion; and 'no effect' was defined as no relief or improvement in symptoms and knee function, and possibly worsening of the condition (27). The following formula was used for evaluating the efficacy of treatment: Total effective rate $=$ (number of patients cured + number of patients with marked effect)/total number of cases.

Knee function was evaluated based on the Lysholm Knee Score Scale (LKSS) score (28) determined prior to and after treatment. Higher scores indicated better knee function. 
Table I. Comparison of clinical data between the groups.

\begin{tabular}{|c|c|c|c|c|}
\hline Item & Experimental group $(\mathrm{n}=32)$ & Control group $(\mathrm{n}=32)$ & $\chi^{2}$ or $\mathrm{t}$ & P-value \\
\hline Age, years & $52.30 \pm 5.44$ & $53.10 \pm 5.74$ & 0.572 & 0.569 \\
\hline Sex & & & 0.063 & 0.802 \\
\hline Male & $15(46.87)$ & $16(50.00)$ & & \\
\hline Female & $17(52.13)$ & $16(50.00)$ & & \\
\hline $\mathrm{BMI}, \mathrm{kg} / \mathrm{m}^{2}$ & $24.45 \pm 2.64$ & $23.81 \pm 2.45$ & 1.005 & 0.318 \\
\hline Course of disease, months & $1.84 \pm 1.24$ & $1.82 \pm 1.36$ & 0.061 & 0.951 \\
\hline Marital status & & 0.075 & 0.784 & \\
\hline Married & $22(68.75)$ & $23(71.87)$ & & \\
\hline Unmarried & $10(31.25)$ & $9(28.13)$ & & \\
\hline VAS & & & 0.169 & 0.918 \\
\hline $0-4$ & $3(9.37)$ & $4(12.5)$ & & \\
\hline $4-7$ & $19(59.38)$ & $18(56.25)$ & & \\
\hline $7-10$ & $10(31.25)$ & $10(31.25)$ & & \\
\hline Area of residence & & 0.063 & 0.802 & \\
\hline Town & $17(52.13)$ & $16(50.00)$ & & \\
\hline Rural & $15(46.87)$ & $16(50.00)$ & & \\
\hline Smoking & & & 0.064 & 0.800 \\
\hline Yes & $14(43.75)$ & $13(40.62)$ & & \\
\hline No & $18(56.25)$ & $19(59.38)$ & & \\
\hline Drinking & & & 0.063 & 0.801 \\
\hline Yes & $14(43.75)$ & $15(46.87)$ & & \\
\hline No & $18(56.25)$ & $17(52.13)$ & & \\
\hline
\end{tabular}

Values are expressed as $\mathrm{n}(\%)$ or the mean \pm standard deviation. BMI, body mass index; VAS, visual analog scale score.

Detection of inflammatory cytokines. Inflammatory cytokines were determined as described previously (29). The patients' knee synovial fluid was sampled prior to and after treatment; the synovial fluid samples were centrifuged at $299 \mathrm{x} g$ for $15 \mathrm{~min}$ at $4^{\circ} \mathrm{C}$ and then stored at $-80^{\circ} \mathrm{C}$. Inflammatory indexes, including IL-6 (cat. no. KIT10395; Sino Biological Inc.), IL-10 (cat. no. BE45601; IBL International) and TNF- $\alpha$ (cat. no. XF16189Q; Shanghai Xinfan Biotechnology Co., Ltd.) were detected through ELISA in strict accordance with the instructions of the kit. The optical density of each well was measured at a wavelength of $450 \mathrm{~nm}$ using a BIOBASE2000 ELISA automatic analyzer (Jinan Biobase Biotechnology Co., Ltd.). From these values, the concentrations of IL-6, IL-10 and TNF- $\alpha$ were then calculated.

Statistical analysis. All statistical analyses were performed using SPSS 24.0 statistical software (IBM Corp.). All graphs were generated using GraphPad 8 (GraphPad Software, Inc.). Enumeration data were expressed as $\mathrm{n}(\%)$ and comparisons between groups were performed using the $\chi^{2}$ test or Fisher's exact test. The Jarque-Bera test was used to test the normality of distribution of the data. Continuous variables were expressed as the mean \pm standard deviation or median (interquartile range). Comparisons of continuous variables were assessed using the paired t-test (before vs. after treatment) or an unpaired t-test (control vs. experimental group). For ordinal variables, Mann-Whitney U tests were used for unpaired comparisons (control vs. experimental group) and Wilcoxon signed-rank tests for paired comparisons (before vs. after treatment). Bonferroni correction was applied for multiple comparisons. $\mathrm{P}<0.05$ was considered to indicate a significant difference.

\section{Results}

Comparison of general characteristics and clinical parameters. No significant differences in terms of age, sex, body mass index, course of disease, marital status, VAS at baseline, area of residence, smoking, drinking and exercise status between the experimental group and the control group were present ( $P>0.05)$, which indicated that the two groups were comparable. The basic data of the two groups are presented in Table I.

VAS at different time-points. After treatment, both the control and experimental group exhibited a lower VAS and experienced pain relief $(\mathrm{P}<0.001)$. The control group after treatment had a higher VAS than the experimental group (4.38 \pm 1.48 and $2.48 \pm 1.25$, respectively) and experienced less pain relief than the experimental group $(\mathrm{P}<0.001$; Table II).

Comparison of the efficacy (\%) of treatment between the groups. Treatment in the control group had a total effectiveness 
Table II. Visual analog scale score of the two groups at different time-points.

\begin{tabular}{lccrr}
\hline Group & Before treatment & After treatment & t & P-value $^{\mathrm{a}}$ \\
\hline Control (n=32) & $6(3)$ & $4(5)$ & 5.610 & $<0.001$ \\
Experimental group $(\mathrm{n}=32)_{\text {P-value }^{\mathrm{b}}}$ & $7(6)$ & $2(3)$ & 12.002 & $<0.001$ \\
\hline
\end{tabular}

${ }^{\mathrm{a} W i l c o x o n}$ signed-rank test; ${ }^{\mathrm{b}}$ Mann-Whitney U test.

Table III. Comparison of the clinical efficacy between the two groups.

\begin{tabular}{lcccc}
\hline Group & Cure & Marked effect & No effect & Total effective rate \\
\hline Control $(\mathrm{n}=32)$ & $13(40.63)$ & $12(37.5)$ & $7(21.87)$ & $25(78.13)$ \\
Experimental group $(\mathrm{n}=32)$ & $18(56.25)$ & $11(34.37)$ & $3(9.38)$ & $29(90.63)$ \\
\hline
\end{tabular}

Values are expressed as n (\%).

Table IV. Comparison of adverse reactions between the two groups.

\begin{tabular}{lcccr}
\hline Group & Infection & Sciatica & Deep venous embolism & Total \\
\hline Experimental group $(\mathrm{n}=32)$ & $2(6.25)$ & $2(6.25)$ & $0(0)$ & $4(12.5)$ \\
Control $(\mathrm{n}=32)$ & $1(3.13)$ & $0(0)^{\mathrm{a}}$ & $0(0)$ & $1(3.13)^{\mathrm{a}}$ \\
\hline
\end{tabular}

Values are expressed as n (\%). ${ }^{\mathrm{a}} \mathrm{P}<0.05$.

rate of $78.13 \%$, with 13 patients cured (40.63\%), 12 patients reporting a marked effect (37.5\%) and no effect reported by 7 patients $(21.87 \%)$. The experimental group had a total effectiveness rate of $90.63 \%$, with 18 patients cured $(56.25 \%)$, 11 patients reporting a marked effect $(34.37 \%)$ and no effect reported by 3 patients $(9.38 \%$; Table III).

Comparison of adverse reactions (\%) between the groups. In the experimental group, two patients suffered an infection $(6.25 \%)$ and two patients had sciatica (6.25\%). In the control group, one patient suffered an infection (3.13\%). There was no evidence of deep venous thrombosis in either group. The experimental group had a higher incidence of adverse reactions than the control group $(\mathrm{P}<0.05$; Table IV).

Evaluation of knee function at different time-points. After treatment, the control group and the experimental group both exhibited higher LKSS values and improved knee joint function $(\mathrm{P}<0.001)$. The control group after treatment had a lower LKSS value than the experimental group (73.31 \pm 9.17 and 84.24 \pm 13.52 , respectively; $\mathrm{P}<0.001$; Table V).

Comparison of IL-6, IL-10 and TNF- $\alpha$ levels. After treatment, both groups exhibited decreased concentrations of IL-6, IL-10 and TNF- $\alpha$ in the knee joint synovial fluid $(\mathrm{P}<0.05)$. The experimental group had lower concentrations of IL-6, IL-10 and TNF- $\alpha$ than the control group ( $\mathrm{P}<0.05$; and Fig. 1).
Comparison between patients with marked effects and those with no effects within the experimental group. The experimental group was divided into a marked effect group, containing 29 patients, and a no effect group, containing 3 patients, based on the clinical efficacy evaluation.

The levels of IL-6 in the marked effect group prior to and after treatment were $49.64 \pm 15.37$ and $23.36 \pm 12.54 \mathrm{pg} / \mathrm{ml}$, respectively, and those of the no effect group were $50.29 \pm 15.35$ and $43.18 \pm 10.24 \mathrm{pg} / \mathrm{ml}$, respectively. The two groups had higher IL-6 levels before treatment $(\mathrm{P}<0.05)$ and the marked effect group had lower IL-6 levels than the no effect group after treatment $(\mathrm{P}<0.05$ Table $\mathrm{VI})$.

The levels of IL-10 in the marked effect group before and after treatment were $51.29 \pm 5.72$ and $25.71 \pm 4.18 \mathrm{pg} / \mathrm{ml}$, respectively, and those of the no effect group were $51.23 \pm 5.73$ and $40.53 \pm 4.39 \mathrm{pg} / \mathrm{ml}$, respectively. The two groups had higher IL-10 levels prior to treatment $(\mathrm{P}<0.05)$ and the marked effect group had lower IL-10 levels than the no effect group after treatment $(\mathrm{P}<0.05)$.

The levels of TNF- $\alpha$ in the marked effect group prior to and after treatment were $405.34 \pm 42.38$ and $304.72 \pm 52.47 \mathrm{ng} / \mathrm{ml}$, respectively, and those of the no effect group were $404.85 \pm 48.34$ and $373.84 \pm 43.10 \mathrm{ng} / \mathrm{ml}$, respectively. The two groups had higher TNF- $\alpha$ levels prior to treatment $(\mathrm{P}<0.05)$ and the marked effect group had lower TNF- $\alpha$ levels than the no effect group after treatment $(\mathrm{P}<0.05)$. These results are presented in Fig. 2. 

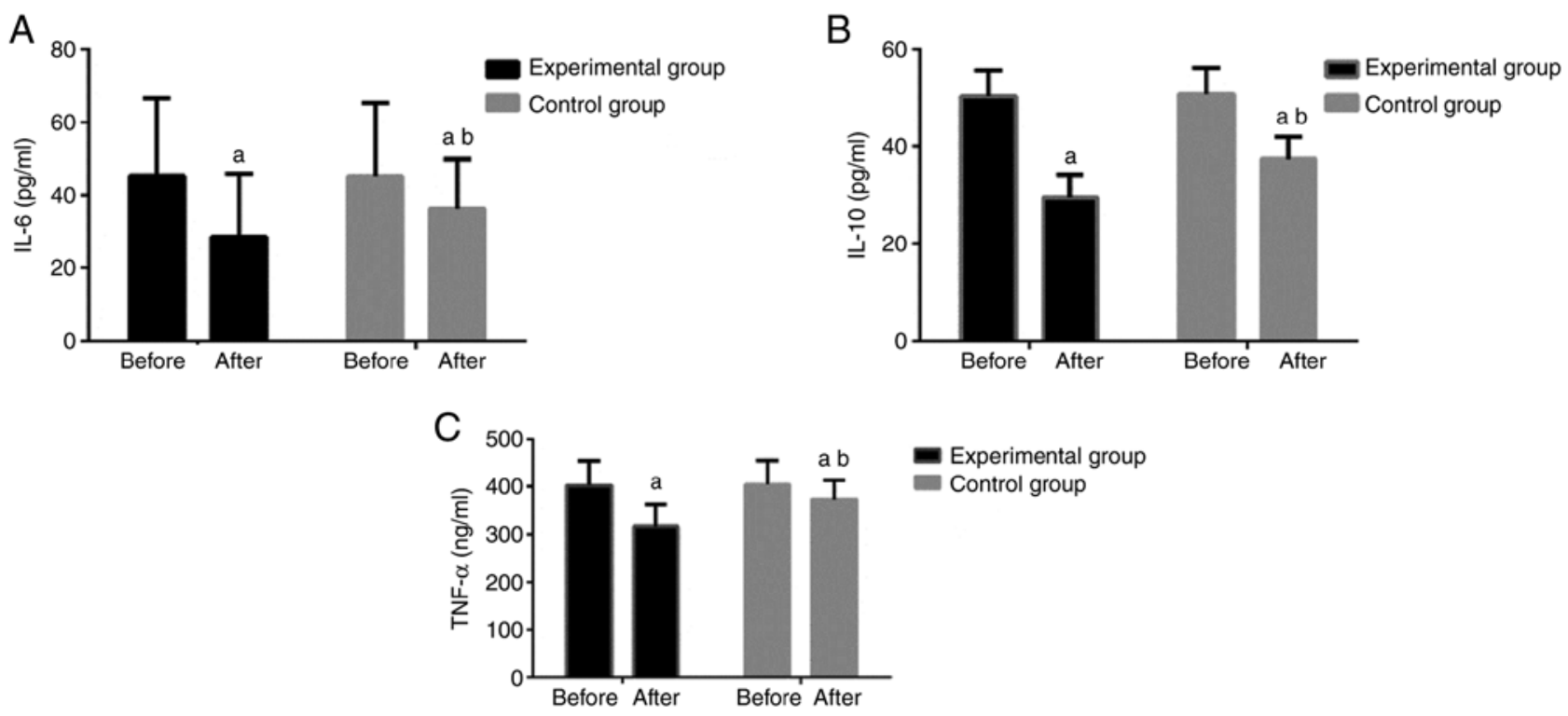

Figure 1. Concentrations of IL-6, IL-10 and TNF- $\alpha$ in the knee synovial fluid from subjects in the control and experimental groups prior to and after treatment. Comparison of the (A) IL-6, (B) IL-10 and (C) TNF- $\alpha$ concentrations in the knee synovial fluid between the control and experimental groups. ${ }^{\mathrm{a}} \mathrm{P}<0.05$ vs. the control or experimental group before/after treatment; ${ }^{\mathrm{b}} \mathrm{P}<0.05 \mathrm{vs}$. the control group or experimental group after treatment.
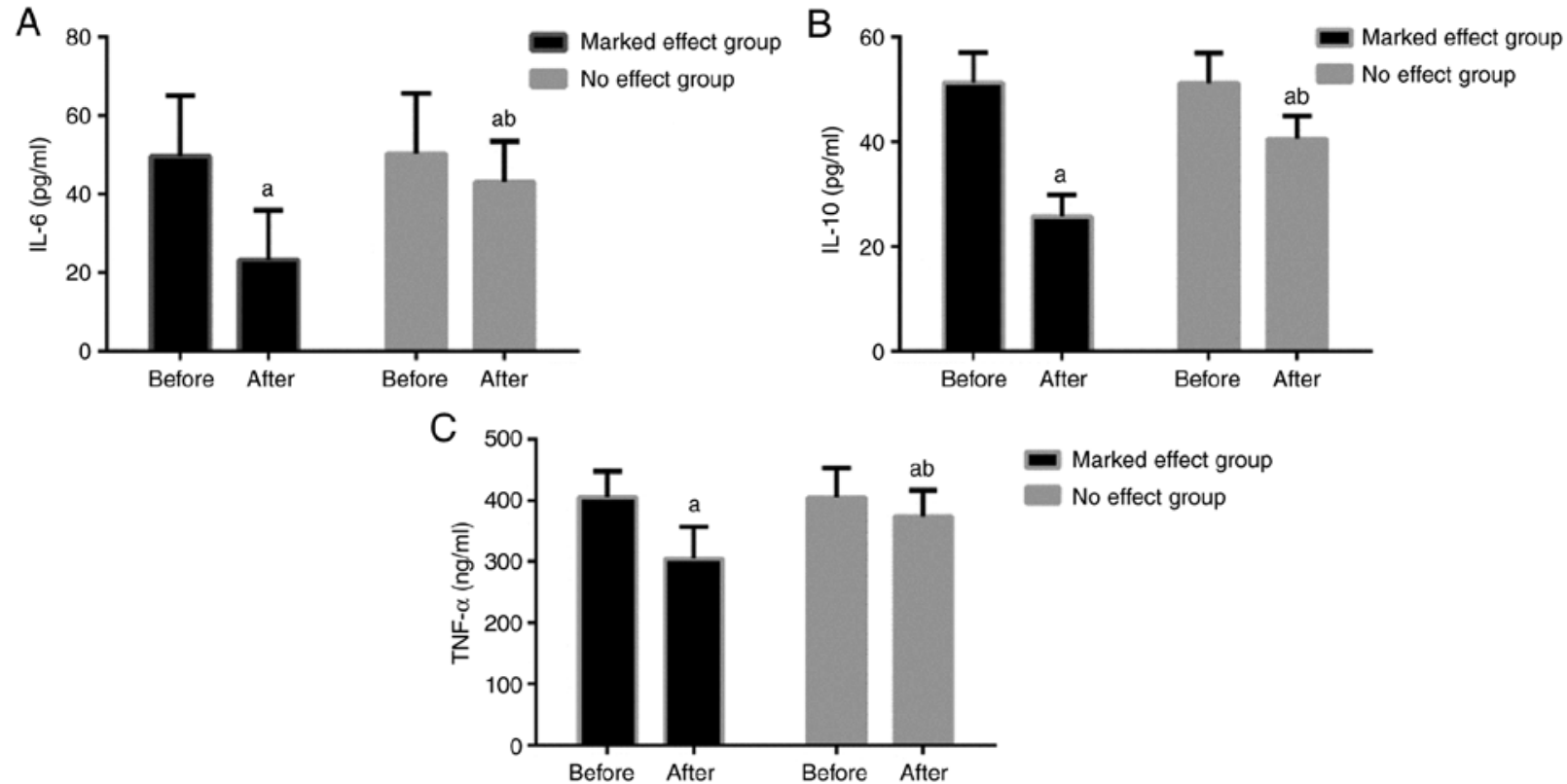

Figure 2. Concentrations of IL-6, IL-10 and TNF- $\alpha$ in knee synovial fluid from subjects in the marked effect and no effect groups prior to and after treatment. Comparisons of the (A) IL-6, (B) IL-10 and (C) TNF- $\alpha$ concentrations in the knee synovial fluid between the marked effect and no effect groups. ${ }^{\mathrm{a}} \mathrm{P}<0.05$ vs. the control or experimental group before/after treatment; ${ }^{\mathrm{b}} \mathrm{P}<0.05$ vs. the no effect or marked effect group after treatment.

\section{Discussion}

Knee OA is a universally disabling joint disease that is frequently accompanied by severe joint pain, swelling, stiffness and loss of movement (30). It is the major cause of knee joint pain and is usually treated with conservative methods (31-34). The European Society for Clinical and Economic Aspects of Osteoporosis and Osteoarthritis recommends NSAIDs as the first choice for the treatment of knee pain, particularly for OA patients who are $>75$ years of age and patients with complications or increased risks of cardiovascular, gastrointestinal or kidney-related side effects (35). However, for certain patients with renal insufficiency, NSAIDs induce high nephrotoxicity (36), indicating the need for novel therapeutic regimens.

Radiofrequency has been adopted for numerous years to treat diseases associated with neuropathic pain (37). Pulsed radiofrequency is a non-pharmacological treatment that has been indicated to reduce severe chronic joint pain; this safe and minimally invasive treatment may be performed in outpatient settings $(38,39)$. Recent studies have investigated the effectiveness of pulsed radiofrequency in patients with chronic pain who were difficult to treat with conservative methods (40) and found pulsed radiofrequency to be an effective and reliable technique for the palliative treatment of chronic pain 
Table V. Evaluation of knee joint function in the two groups at different time-points.

\begin{tabular}{lcccr}
\hline Group & Before treatment & After treatment & $\mathrm{t}^{\mathrm{a}}$ & P-value \\
\hline Control $(\mathrm{n}=32)$ & $41.34 \pm 7.24$ & $73.31 \pm 9.17$ & 21.286 & $<0.001$ \\
Experimental group $(\mathrm{n}=32)$ & $42.19 \pm 7.18$ & $84.24 \pm 13.52$ & 18.751 & $<0.001$ \\
$\mathrm{t}^{\mathrm{b}}$ & 0.472 & 3.785 & & \\
P-value & 0.638 & $<0.001$ & & \\
\hline
\end{tabular}

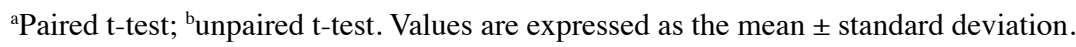

Table VI. Comparison of IL-6, IL-10 and TNF- $\alpha$ levels between the two groups before and after treatment.

\begin{tabular}{|c|c|c|c|c|c|c|c|c|}
\hline \multirow[b]{2}{*}{ Index } & \multicolumn{2}{|c|}{ Experimental group } & \multirow[b]{2}{*}{$\mathrm{t}$} & \multirow[b]{2}{*}{ P-value } & \multicolumn{2}{|c|}{ Control group } & \multirow[b]{2}{*}{$\mathrm{t}$} & \multirow[b]{2}{*}{ P-value } \\
\hline & Before & After & & & Before & After & & \\
\hline IL-6, pg/ml & $45.31 \pm 21.38$ & $28.60 \pm 17.27^{\mathrm{a}}$ & 2.467 & 0.020 & $45.21 \pm 20.23$ & $36.39 \pm 13.43^{\mathrm{a}, \mathrm{b}}$ & 2.452 & 0.0262 \\
\hline IL- $10, \mathrm{pg} / \mathrm{ml}$ & $50.48 \pm 5.23$ & $29.54 \pm 4.64^{\mathrm{a}}$ & 11.56 & $<0.001$ & $50.86 \pm 5.39$ & $37.43 \pm 4.59^{\mathrm{a}, \mathrm{b}}$ & 7.982 & $<0.001$ \\
\hline TNF- $\alpha, \mathrm{ng} / \mathrm{ml}$ & $402.14 \pm 53.14$ & $316.35 \pm 46.53^{a}$ & 9.864 & $<0.001$ & $403.78 \pm 52.29$ & $372.71 \pm 40.26^{\mathrm{a}, \mathrm{b}}$ & 3.271 & 0.003 \\
\hline
\end{tabular}

Values are expressed as the mean \pm standard deviation. ${ }^{\mathrm{a}} \mathrm{P}<0.05 \mathrm{vs}$. the experimental group before treatment (paired t-test); ${ }^{\mathrm{b}} \mathrm{P}<0.05$ comparison with the experimental group after treatment (unpaired t-test).

in patients with gonarthritis. However, only a small number of clinical studies $(41,42)$ on repeated intra-articular pulsed radiofrequency for the treatment of knee joint pain have been performed. It has been reported that the expression levels of cytokines, such as IL-1 receptor $\alpha$, IL-6, IL-8, IL-10, IL-15 and monocyte chemo-attractant protein- 1 are increased in the synovial fluid of patients with traumatic anklebone arthritis, due to inflammatory injury (43). However, only a small number of studies $(16,44)$ on the changes in the levels of inflammatory cytokines in the synovial fluid of patients with knee joint pain undergoing repeated treatment with intra-articular pulsed radiofrequency have been performed, which is worth investigating.

The results of the present study revealed that after treatment with intra-articular pulsed radiofrequency, the subjects in the experimental group had a lower VAS and higher total effectiveness rate than those in the control group, while experiencing a higher degree of pain relief and improved knee joint function. This indicated that the efficacy of the treatment in the experimental group was better than that in the control group. Nagar et al (45) compared pulsed radiofrequency therapy and continuous radiofrequency therapy in the treatment of patients with facet joint lower back pain and demonstrated that continuous radiofrequency therapy was more effective, which is similar to the results of the present study. In the present study, the subjects in the experimental group had a higher incidence of adverse reactions than those in the control group. It may be hypothesized that the increase in the number of treatments in the experimental group led to an increase in the number of adverse reactions, which suggests that close attention must be paid to whether patients are affected by other diseases during treatment.

After treatment, both groups had decreased concentrations of IL-6, IL-10 and TNF- $\alpha$ in the synovial fluid of the knee joint. The experimental group performed better than the control group with regard to these indexes; the marked effect group had lower concentrations of IL-6, IL-10 and TNF- $\alpha$ than the control group, which was consistent with the results of the study by Li et al (46) on the correlation of changes in the serum inflammatory cytokines with knee joint pain symptoms. Their study revealed that the degree of pain was closely related to TNF- $\alpha$ levels. It may be hypothesized that repeated intra-articular pulsed radiofrequency may reduce the inflammatory response and lower the degree of knee pain in patients by inhibiting the expression of IL-6, IL-10 and TNF- $\alpha$ in the synovial fluid. By assessing the duration of pulsed radiofrequency in alleviating neuropathic pain, Ramzy et al (47) determined that a prolonged duration of pulsed radiofrequency had a better analgesic effect and that an increase in duration was associated with a significant decrease in IL-6 and TNF- $\alpha$ levels; these results support the present hypothesis that pulsed radiofrequency reduces the production of pro-inflammatory cytokines. Moffett et al (48) studied the regulatory mechanism of pulsed radiofrequency energy on peripheral pain and determined that the levels of primary transcription products produced by structural gene pre-mRNA, an endogenous opiate-like substance, and corresponding opioid peptide levels were increased, which further supports the present hypothesis.

The present study confirmed that repeated intra-articular pulsed radiofrequency is a feasible treatment method for patients with knee joint pain based on the comparison of single and repeated treatments. However, there are certain limitations to the present study. For instance, the number of research subjects included in the study was low and all patients undergoing repeated treatment were treated at the same time. The treatment time of the patients was not determined based on their individual conditions; thus, the patients' pain relief was 
inconsistent. The patients' age was associated with certain problems, e.g. inflammatory mediator levels in a 47-year-old patient may not be comparable with those of a 60-year-old; however, the median age was similar among groups. Of note, there was a lack of homogeneity during patient selection. In future studies, it will be endeavored to improve the study design and screen patients according to strict inclusion and exclusion criteria in order to obtain more consistent results in the future.

In conclusion, repeated intra-articular pulsed radiofrequency is an effective method for the treatment of knee joint pain with a good analgesic effect and it may be used in clinical practice.

\section{Acknowledgements}

Not applicable.

\section{Funding}

No funding was received.

\section{Availability of data and materials}

The datasets used and/or analyzed during the current study are available from the corresponding author upon reasonable request.

\section{Authors' contributions}

All authors conceived and designed the study and interpreted the results of the experiments. JZ and ZW performed experiments and analyzed data. HX prepared figures and drafted the manuscript. ZY edited and revised the manuscript, designed the current study and analyzed the data. All authors read and approved the final version of the manuscript. JZ and HX confirm the authenticity of all the raw data.

\section{Ethics approval and consent to participate}

This study was approved by the Ethics Committee of Caoxian People's Hospital (Caoxian, China) and all research subjects signed an informed consent form.

\section{Patient consent for publication}

Not applicable.

\section{Competing interests}

The authors declare that they have no competing interests.

\section{References}

1. Teixeira JM, Bobinski F, Parada CA, Sluka KA and Tambeli CH: $\mathrm{P} 2 \mathrm{X} 3$ and $\mathrm{P} 2 \mathrm{X} 2 / 3$ receptors play a crucial role in articular hyperalgesia development through inflammatory mechanisms in the knee joint experimental synovitis. Mol Neurobiol 54: 6174-6186, 2017.

2. McWilliams DF, Ferguson E, Young A, Kiely PD and Walsh DA Discordant inflammation and pain in early and established rheumatoid arthritis: Latent Class Analysis of Early Rheumatoid Arthritis Network and British Society for Rheumatology Biologics Register data. Arthritis Res Ther 18: 295, 2016.
3. Hirschmann MT and Müller W: Complex function of the knee joint: The current understanding of the knee. Knee Surg Sports Traumatol Arthrosc 23: 2780-2788, 2015.

4. Provenza JR, Shinjo SK, Silva JM, Peron CR and Rocha FA: Combined glucosamine and chondroitin sulfate, once or three times daily, provides clinically relevant analgesia in knee osteoarthritis. Clin Rheumatol 34: 1455-1462, 2015.

5. Liu J and Wang F: Preoperative celecoxib analgesia is more efficient and equally tolerated compared to postoperative celecoxib analgesia in knee osteoarthritis patients undergoing total knee arthroplasty: A randomized, controlled study. Medicine (Baltimore) 97: e13663, 2018.

6. Tellegen AR, Rudnik-Jansen I, Pouran B, de Visser HM, Weinans HH, Thomas RE, Kik MJL, Grinwis GCM, Thies JC, Woike N, et al: Controlled release of celecoxib inhibits inflammation, bone cysts and osteophyte formation in a preclinical model of osteoarthritis. Drug Deliv 25: 1438-1447, 2018.

7. Inoue T, Iijima H, Arimitsu J, Hagihara K, Kawai S, Shiraishi E, Hiyama S, Mukai A, Shinzaki S, Nishida T, et al: Amelioration of small bowel injury by switching from nonselective nonsteroidal anti-inflammatory drugs to celecoxib in rheumatoid arthritis patients: A pilot study. Digestion 89: 124-132, 2014.

8. Wang X, Wei L, Lv Z, Zhao B, Duan Z, Wu W, Zhang B and Wei X: Proximal fibular osteotomy: A new surgery for pain relief and improvement of joint function in patients with knee osteoarthritis. J Int Med Res 45: 282-289, 2017.

9. Lindquist $J$ and Bäckryd E: Pulsed radiofrequency in clinical practice - A retrospective analysis of 238 patients with chronic non-cancer pain treated at an academic tertiary pain centre. Scand J Pain 12: 68-73, 2016.

10. Huang YH, Hou SY, Cheng JK, Wu CH and Lin CR: Pulsed radiofrequency attenuates diabetic neuropathic pain and suppresses formalin-evoked spinal glutamate release in rats. Int J Med Sci 13: 984-991, 2016.

11. Albayrak I, Apiliogullari S, Onal O, Gungor C, Saltali A and Levendoglu F: Pulsed radiofrequency applied to the dorsal root ganglia for treatment of post-stroke complex regional pain syndrome: A case series. J Clin Anesth 33: 192-197, 2016.

12. Erdem Y and Sir E: The efficacy of ultrasound-guided pulsed radiofrequency of genicular nerves in the treatment of chronic knee pain due to severe degenerative disease or previous total knee arthroplasty. Med Sci Monit 25: 1857-1863, 2019.

13. Vas L, Pai R, Khandagale N and Pattnaik M: Pulsed radiofrequency of the composite nerve supply to the knee joint as a new technique for relieving osteoarthritic pain: A preliminary report. Pain Physician 17: 493-506, 2014.

14. Bigoni M, Turati M, Zatti G, Gandolla M, Sacerdote P, Piatti M, Castelnuovo A, Rigamonti L, Munegato D, Franchi S, et al: Intra-articular cytokine levels in adolescent patients after anterior cruciate ligament tear. Mediators Inflamm 2018: 4210593, 2018.

15. Shin SM, Kwak SG, Lee DG and Chang MC: Clinical effectiveness of intra-articular pulsed radiofrequency compared to intra-articular corticosteroid injection for management of Atlanto-occipital joint pain: A prospective randomized controlled pilot study. Spine 43: 741-746, 2018.

16. Filippiadis D, Charalampopoulos G, Mazioti A, Alexopoulou E, Vrachliotis T, Brountzos E, Kelekis $\mathrm{N}$ and Kelek is A: Interventional radiology techniques for pain reduction and mobility improvement in patients with knee osteoarthritis. Diagn Interv Imaging 100: 391-400, 2019.

17. Ogura T, Suzuki M, Sakuma Y, Yamauchi K, Orita S, Miyagi M, Ishikawa T, Kamoda H, Oikawa Y, Kanisawa I, et al: Differences in levels of inflammatory mediators in meniscal and synovial tissue of patients with meniscal lesions. J Exp Orthop 3: 7, 2016.

18. Li S, Wan J, Anderson W, Sun H, Zhang H, Peng X, Yu Z, Wang T, Yan X and Smith W: Downregulation of IL-10 secretion by Treg cells in osteoarthritis is associated with a reduction in Tim-3 expression. Biomed Pharmacother 79: 159-165, 2016.

19. Runhaar J, Beavers DP, Miller GD, Nicklas BJ, Loeser RF, Bierma-Zeinstra S and Messier SP: Inflammatory cytokines mediate the effects of diet and exercise on pain and function in knee osteoarthritis independent of BMI. Osteoarthritis Cartilage 27: 1118-1123, 2019.

20. Singh JA, Noorbaloochi S and Knutson KL: Cytokine and neuropeptide levels are associated with pain relief in patients with chronically painful total knee arthroplasty: A pilot study. BMC Musculoskelet Disord 18: 17, 2017.

21. Bigoni M, Zanchi N, Omeljaniuk RJ, Zatti G, Locatelli V, Torsello A and Turati M: Role of interleukin-10 in the synovial fluid of the anterior cruciate ligament injured knee. Eur Rev Med Pharmacol Sci 23: 932-940, 2019. 
22. Siqueira MB, Frangiamore S, Klika AK, Gajewski N Barsoum WK and Higuera CA: Comparison of synovial fluid cytokine levels between traumatic knee injury and end-stage osteoarthritis. J Knee Surg 30: 128-133, 2017.

23. Wassilew GI, Lehnigk U, Duda GN, Taylor WR, Matziolis G and Dynybil C: The expression of proinflammatory cytokines and matrix metalloproteinases in the synovial membranes of patients with osteoarthritis compared with traumatic knee disorders. Arthroscopy 26: 1096-1104, 2010.

24. Cuellar VG, Cuellar JM, Golish SR, Yeomans DC and Scuderi GJ: Cytokine profiling in acute anterior cruciate ligament injury. Arthroscopy 26: 1296-1301, 2010.

25. Brandt KD, Fife RS, Braunstein EM and Katz B: Radiographic grading of the severity of knee osteoarthritis: Relation of the Kellgren and Lawrence grade to a grade based on joint space narrowing, and correlation with arthroscopic evidence of articular cartilage degeneration. Arthritis Rheum 34: 1381-1386, 1991.

26. Tashiian RZ, Hung M, Keener JD, Bowen RC, McAllister J, Chen W, Ebersole G, Granger EK and Chamberlain AM: Determining the minimal clinically important difference for the American Shoulder and Elbow Surgeons score, Simple Shoulder Test, and visual analog scale (VAS) measuring pain after shoulder arthroplasty. J Shoulder Elbow Surg 26: 144-148, 2017.

27. Manimunda SP, Vijayachari P, Uppoor R, Sugunan AP, Singh SS Rai SK, Sudeep AB, Muruganandam N, Chaitanya IK and Guruprasad DR: Clinical progression of chikungunya fever during acute and chronic arthritic stages and the changes in joint morphology as revealed by imaging. Trans R Soc Trop Med Hyg 104: 392-399, 2010

28. Collins NJ, Misra D, Felson DT, Crossley KM and Roos EM: Measures of knee function: International Knee Documentation Committee (IKDC) Subjective Knee Evaluation Form, Knee Injury and Osteoarthritis Outcome Score (KOOS), Knee Injury and Osteoarthritis Outcome Score Physical Function Short Form (KOOS-PS), Knee Outcome Survey Activities of Daily Living Scale (KOS-ADL), Lysholm Knee Scoring Scale, Oxford Knee Score (OKS), Western Ontario and McMaster Universities Osteoarthritis Index (WOMAC), Activity Rating Scale (ARS), and Tegner Activity Score (TAS). Arthritis Care Res (Hoboken) 63 (Suppl 11): S208-S228, 2011.

29. Zhai KF, Duan H, Khan GJ, Xu H, Han FK, Cao WG, Gao GZ, Shan LL and Wei ZJ: Salicin from Alangium chinense ameliorates rheumatoid arthritis by modulating the Nrf2-HO-1-ROS pathways. J Agric Food Chem 66: 6073-6082, 2018.

30. Wallace IJ, Worthington S, Felson DT, Jurmain RD, Wren KT, Maijanen H, Woods RJ and Lieberman DE: Knee osteoarthritis has doubled in prevalence since the mid-20th century. Proc Nat Acad Sci USA 114: 9332-9336, 2017.

31. Aciksoz S, Akyuz A and Tunay S: The effect of self-administered superficial local hot and cold application methods on pain, functional status and quality of life in primary knee osteoarthritis patients. J Clin Nurs 26: 5179-5190, 2017.

32. Conaghan PG, Hunter DJ, Cohen SB, Kraus VB, Berenbaum F, Lieberman JR, Jones DG, Spitzer AI, Jevsevar DS, Katz NP, et al FX006-2014-008 participating investigators: Effects of a single intra-articular injection of a microsphere formulation of triamcinolone acetonide on knee osteoarthritis pain: a double-blinded, randomized, placebo-controlled, multinational study. J Bone Joint Surg Am 100: 666-677, 2018.

33. Yilmaz M, Sahin M and Algun ZC: Comparison of effectiveness of the home exercise program and the home exercise program taught by physiotherapist in knee osteoarthritis. J Back Musculoskeletal Rehabil 32: 161-169, 2019.
34. Özkuk K, Gürdal H, Karagülle M, Barut Y, Eröksüz R and Karagülle MZ: Balneological outpatient treatment for patients with knee osteoarthritis; an effective non-drug therapy option in daily routine? Int J Biometeorol 61: 719-728, 2017.

35. Rannou F, Pelletier JP and Martel-Pelletier J: Efficacy and safety of topical NSAIDs in the management of osteoarthritis: Evidence from real-life setting trials and surveys. Semin Arthritis Rheum 45 (Suppl 4): S18-S21, 2016.

36. Strawson J: Nonsteroidal anti-inflammatory drugs and cancer pain. Curr Opin Support Palliat Care 12: 102-107, 2018

37. Huang RY, Liao CC, Tsai SY, Yen CT, Lin CW, Chen TC, Lin WT, Chang CH and Wen YR: Rapid and delayed effects of pulsed radiofrequency on neuropathic pain: Electrophysiological, molecular, and behavioral evidence supporting long-term depression. Pain Physician 20: E269-E283, 2017.

38. Gulec E, Ozbek H, Pektas S and Isik G: Bipolar versus unipolar intraarticular pulsed radiofrequency thermocoagulation in chronic knee pain treatment: A prospective randomized trial. Pain Physician 20: 197-206, 2017.

39. Eyigor C, Eyigor S, Akdeniz S and Uyar M: Effects of intra-articular application of pulsed radiofrequency on pain, functioning and quality of life in patients with advanced knee osteoarthritis. J Back Musculoskeletal Rehabil 28: 129-134, 2015.

40. Masala S, Fiori R, Raguso M, Morini M, Calabria E and Simonetti G: Pulse-dose radiofrequency for knee osteoartrithis. Cardiovasc Intervent Radiol 37: 482-487, 2014.

41. Schianchi PM, Sluijter ME and Balogh SE: The treatment of joint pain with intra-articular pulsed radiofrequency. Anesth Pain Med 3: 250-255, 2013

42. Rahimzadeh P, Imani F, Faiz SH, Entezary SR, Nasiri AA and Ziaeefard M: Investigation the efficacy of intra-articular prolotherapy with erythropoietin and dextrose and intra-articular pulsed radiofrequency on pain level reduction and range of motion improvement in primary osteoarthritis of knee. J Res Med Sci 19: 696-702, 2014

43. Adams SB Jr, Nettles DL, Jones LC, Miller SD, Guyton GP and Schon LC: Inflammatory cytokines and cellular metabolites as synovial fluid biomarkers of posttraumatic ankle arthritis. Foot Ankle Int 35: 1241-1249, 2014.

44. Filippiadis D, Velonakis G, Mazioti A, Konstantos C, Brountzos E, Kelekis N and Kelekis A: Intra-articular application of pulsed radiofrequency combined with viscosupplementation for improvement of knee osteoarthritis symptoms: A single centre prospective study. Int J Hyperthermia 34: 1265-1269, 2018.

45. Nagar VR, Birthi P, Grider JS and Asopa A: Systematic review of radiofrequency ablation and pulsed radiofrequency for management of cervicogenic headache. Pain Physician 18: 109-130, 2015.

46. Li S, An R, Wang Z, Kuang L, Tan W and Fang C: Correlation analysis of bone marrow edema degree and serum inflammatory factors change with knee joint pain symptoms in patients with bone contusion around the knee joint. Zhongguo Xiu Fu Chong Jian Wai Ke Za Zhi 28: 615-619, 2014 (In Chinese).

47. Ramzy EA, Khalil KI, Nour EM, Hamed MF and Taha MA Evaluation of the effect of duration on the efficacy of pulsed radiofrequency in an animal model of neuropathic pain. Pain Physician 21: 191-198, 2018.

48. Moffett J, Fray LM and Kubat NJ: Activation of endogenous opioid gene expression in human keratinocytes and fibroblasts by pulsed radiofrequency energy fields. J Pain Res 5: 347-357, 2012.

This work is licensed under a Creative Commons Attribution 4.0 International (CC BY-NC 4.0) License 